\title{
Interruptions experienced by nurses during preparation and administration of medications at the patient's bedside/corridor: Duration and causes, Turkey
}

\author{
Gülbanu Zencir*1, Nazike Duruk², İsmet Eșer ${ }^{3}$ \\ ${ }^{1}$ Fundamentals of Nursing Department, Faculty of Health Sciences, Pamukkale University, Denizli, Turkey \\ ${ }^{2}$ Fundamentals of Nursing Department, Faculty of Health Sciences, Osmangazi University, Eskișehir, Turkey \\ ${ }^{3}$ Fundamentals of Nursing Department, Nursing Faculty, Ege University, Izmir, Turkey
}

Received: December 9, 2019

Accepted: January 13, 2020

Online Published: January 15, 2020

DOI: $10.5430 / \mathrm{cns} . v 8 \mathrm{n} 1 \mathrm{p} 21$

URL: https://doi.org/10.5430/cns.v8n1p21

\begin{abstract}
Background: Nurses experience many interruptions during drug administration. Interruptions threaten the safety of patients and nurses in health institutions.

Aim: This study aimed to investigate the interruptions experienced by nurses during preparation and administration of medications at the patient's bedside/corridor in different clinics.

Methods: Interruptions was determined by several observations. Observations carried out during nurses' medication process in internal medicine and surgical services (by two researchers). Sixty observation were made in total by two researchers.

Results: Interruptions were detected at least once in the preparations and administration process in all of the observations. The interruption frequency in preparation, administration and the whole process were statistically significant different between the services. The interruptions in the general surgery service were higher than the internal medicine service. The interruption frequency was significantly higher during the preparation process in internal medicine service and administration process in general surgery service.

Conclusions: Interruptions during nurses' medication process at the patient's bedside or in the corridor was commonly observed, especially in the general surgery service.
\end{abstract}

Key Words: Medication errors, Nursing, Patient safety, Inpatients

\section{INTRODUCTION}

There are differences regarding medication processes in the way they are practiced in different clinics, health institutions, cities and countries. Especially, regarding the preparation of medications, medication rooms are preferred in some hospitals while the patient's bedside/corridor is preferred in others.
Conditions such as nursing practices in clinics, clinical protocols, properties of medications etc. determine this preference. The decision on how to carry out the medication process can have an impact on the interruptions experienced by nurses during this process. For nurses, it is not possible to work without interruption. ${ }^{[1]}$ These interruptions can lead to risks

\footnotetext{
*Correspondence: Gülbanu Zencir; Email: gzencir@pau.edu.tr; Address: Fundamentals of Nursing Department, Faculty of Health Sciences, Pamukkale University, Denizli, Turkey.
} 
and errors for nurses and patients. ${ }^{[2-4]}$

Failure to attentionally administer medications is very risky and threatens the safety of patients. Medication errors that are defined as "... a preventable event" ${ }^{[5]}$ are ranked fifth in the list of adverse events announced. ${ }^{[6]}$ Medication errors are one of the most common errors encountered by the hospitalized patients. ${ }^{[6-8]}$ In the literature, it was expressed that individuals encountered at least one medication error at the rate of $2 \%$ to $14 \%$ during their hospital stay. ${ }^{[9]}$

In the medication process, nurses are primarily responsible for medication safety which includes preparation and administration. ${ }^{[10,11]}$ Recent studies reveal that there has been an increase in medication error rates. ${ }^{[12]}$

Work environments harbor many latent conditions that threaten patient safety. These errors can be related to individual acts as well as the system. ${ }^{[10,13,14]}$ In the literature study conducted by Monteiro et al., ${ }^{[15]}$ it was stated that interruptions supported the formation of errors in the field of health. The medication process is a condition that requires nurses' constant attention. In the case of sustained attention, the person must maintain the arousal state and focus without being given a break while executing a certain task. Divided attention is defined as the ability to attend to two or more stimuli at the same time. Nurses encounter multiple stimuli simultaneously during medication and their attention is divided. ${ }^{[3,16]}$ Dickson \& Flynn ${ }^{[17]}$ stated that nurses who were interrupted due to reasons such as calling the physician, responding to the questions of families and supporting caregivers had their attention divided temporarily; thus, had to refocus on the medication process.

It is almost impossible for nurses to work without interruption. ${ }^{[1]}$ Throughout the preparation and administration of medications, nurses encounter multiple conditions which divide their attention such as stimuli from the environment,lack of staff and lack of equipment. ${ }^{[18]}$ The literature demonstrates that nurses are interrupted during the preparation/administration of medications ${ }^{[11,17-19]}$ and that this interruption causes a risk, ${ }^{[2,4]}$ contributing to errors and causing nurses to commit errors. ${ }^{[1,20,21]}$

Interruptions encountered by nurses during the preparation and administration of medications are among the conditions that either cause or contribute to errors. ${ }^{[22]}$ In all countries, especially developing countries, interruptions should be given more space on the agenda and should be listed in the first place among the causes of medication errors committed by nurses. Interruptions and their causes must be revealed to institution managers to provide a safer environment for nurses and patients. Determining the factors causing interruptions and efforts to eliminate them are crucial for preventing the errors in the administration of medications.

Awareness of this issue has started to change in recent years. ${ }^{[20]}$ As in the literature, studies conducted in our country on medication errors generally focused on the causes of errors, as well. However, interruptions have not been included among the conditions causing medication errors, except for one study. The studies on the interruptions encountered by nurses during their medication preparation at the patient's bedside and the causes as well as the duration of these interruptions are limited.

\section{METHODS}

\subsection{Hypotheses of this research}

(1) The area in which the medication is prepared affects the interruption of nurses.

(2) Nurses have different types of interruptions in drug preparation and administration process.

(3) Interruptions vary according to clinics.

\subsection{Study design and participants}

This descriptive and cross-sectional study was conducted at a university hospital located in the Western Anatolia Region of Turkey in the internal medicine and general surgery services through direct observation methods between July 15 and August 30, 2013.

In this study, the interruptions, their causes, number, duration and the factors causing them were observed when the medication was prepared and administered in the patient room.

\subsection{Data collection}

The data of the study was collected through observation during the medication process (preparation and administration) of the nurses with the medication cart at the patient's bedside in the two services where the research was conducted. Ten am was the preferred time for data collection. The reason for this is that this hour is busier in terms of the clinical process (physician visits, pre-op and post-op patient flow, admission-discharge process, etc.) and the number of increased medications.

In the study, a total of 60 observations were made (general surgery service-GSS $n=30$, internal medicine service-IMS $\mathrm{n}=30$ ). Observations were performed simultaneously by two researchers. The average number of nurses serving in both services during the observation period is 4 while the number of nurses observed during the medication is 1 .

The data collected (number of patients and nurses in the 
service, number of medications prepared and administered, observations of medication preparation and administration, interruptions, number and duration of interruptions, person(s) and factors causing interruptions) were recorded in the Medication Preparation and Administration Observation Checklist. This checklist was prepared by the researchers using the relevant sources. ${ }^{[11,23-25]}$ A stopwatch (Loyka brand) was used to determine the durations of interruptions.

Considering the duration of interruptions as a factor causing distraction, interruptions have been classified into two different categories: 1) short interruptions which are defined as the interruptions experienced by nurses for another reason (giving information, positioning etc.) during the preparation and administration of the medication without leaving the patient's bedside/medication cart and 2) pauses to the medication processes causing a long break which are defined as long-term interruptions when nurses leave the patient's bedside/medication cart to perform another task (welcoming post-op patients, new arrivals etc.) and return to the preparation and administration of the medication.

In the study, the interruptions were evaluated as short interruption, pause to medication and total interruptions (including both short interruptions and pauses to medication).

\subsection{Data analysis}

SPSS Package was used to evaluate the data including a descriptive analysis of number, percentage and mean standard deviation and as analytical statistics; Chi-square, correlation,
Mann Whitney $U$ and $t$ test were used.

For the comparison of the condition of interruption according to services, chi-square analysis was used while the Mann Whitney $U$ test was used to compare the number and duration of interruptions.

\subsection{Strengths and limitations}

The limitation of this study is that it is performed in two clinics of a single hospital in a developing country. In these countries, there are significant problems in health infrastructure and nursing services are affected. The results obtained should be evaluated within this limitation. Therefore, the results of the study cannot be generalized for other countries.

\subsection{Ethics}

Verbal and written informed consent was obtained from the participants. Necessary permissions obtained from the hospital for this study. Ethical approval was obtained from the Pamukkale University Medical Ethics Committee (IRB 2012-62).

\section{RESUlts}

Descriptive information about the medication process is given in Table 1. As a result of observations; average number of drugs per nurse $9.2 \pm 2.6$; average number of patients per nurse $7.9 \pm 1.4$; average duration of preparation (second) $28.2 \pm 17.7$; the mean duration of administration (second) was $52.2 \pm 12.8$ and the total average number of drug mean was $36.5 \pm 9.4$.

Table 1. Frequency of patient, nurse and drug on observed clinics

\begin{tabular}{|c|c|c|c|c|c|}
\hline & \multicolumn{2}{|c|}{ General surgery service } & \multicolumn{2}{|c|}{ Internal medicine service } & \multirow[b]{2}{*}{$p$} \\
\hline & Mean $\pm S D$ & $\begin{array}{c}\text { Median } \\
\text { (quartile) }\end{array}$ & Mean $\pm S D$ & $\begin{array}{c}\text { Median } \\
\text { (quartile) }\end{array}$ & \\
\hline Number of patient & $32.2 \pm 5.1$ & $33(28-37)$ & $17.9 \pm 4.6$ & $15.5(14-23)$ & $<.001^{* * *}$ \\
\hline Number of drug per nurse & $9.2 \pm 2.6$ & $8.9(7.3-10.6)$ & $6.4 \pm 2.3$ & $5.9(4.6-8.0)$ & $<.001^{* * *}$ \\
\hline Number of patient per nurse & $7.9 \pm 1.4$ & $8.0(6.5-9.3)$ & $4.4 \pm 1.6$ & $3.9(3.4-5.0)$ & $<.001^{* * *}$ \\
\hline Duration of preparation (second) & $28.2 \pm 17.7$ & $23(18-34)$ & $16.2 \pm 5.8$ & $15.5(12-18)$ & $<.001^{* * * *}$ \\
\hline Duration of administration (second) & $52.2 \pm 12.8$ & $51.5(41-62)$ & $30.8 \pm 12.2$ & $32(22-39.5)$ & $<.001^{* * *}$ \\
\hline \multicolumn{6}{|l|}{ Number of drug } \\
\hline Total & $36.5 \pm 9.4$ & $36.5(29-43)$ & $27.0 \pm 9.1$ & $26.5(18-34)$ & $<.001^{* * *}$ \\
\hline IV & $15.2 \pm 7.9$ & $13(9-20)$ & $3.0 \pm 2.1$ & $2(2-4)$ & $<.001^{* * *}$ \\
\hline $\mathrm{SC}$ & $4.7 \pm 2.1$ & $5(3-6)$ & $2.3 \pm 1.4$ & $2(1-3)$ & $<.001^{* * *}$ \\
\hline Oral & $11.3 \pm 5.8$ & $10(7-14)$ & $13.4 \pm 6.8$ & $11.5(8-18)$ & $>.05$ \\
\hline Infusion & $2.1 \pm 2.2$ & $2(0-4)$ & $4.2 \pm 2.0$ & $4(3-5)$ & $<.001^{* * *}$ \\
\hline Other & $0.2 \pm 0.5$ & $0(0-0)$ & $4.0 \pm 1.3$ & $3.5(3-5)$ & $.037^{* *}$ \\
\hline
\end{tabular}

Note. ${ }^{*} p<.05 ;{ }^{* * *} p<.001$ 
In all the observations conducted during the medication process (preparation and administration), total interruptions were determined. Again, in all the observations, the rate of interruptions during preparation were $95 \%$, while it was $98.3 \%$ in the administration process. The interruptions during the preparation process were higher in IMS $(96.7 \%)$ compared to GSS $(93.3 \%)$, while they were higher in GSS (100\%) than in IMS $(96.7 \%)$ during the administration process.

The median of total interruptions was found to be 13; and it was 8.5 for the preparation process while it was found to be 5 for the administration of the medications (see Table 2). Statistically significant differences were found between the services regarding the frequency of preparation $(p<.001)$, administration $(p<.001)$ and total interruption $(p=.036)$ (see Table 3).

Table 2. Duration and frequency of interruption (short interruptions, pause to medication, total) in medication process

\begin{tabular}{|c|c|c|c|c|c|c|}
\hline & \multicolumn{2}{|c|}{ Frequency of short interruptions } & \multicolumn{2}{|c|}{ Frequency of pause to medication } & \multicolumn{2}{|c|}{ Frequency of total interruptions } \\
\hline & Mean $\pm S D$ & Median (quartile) & Mean $\pm S D$ & Median (quartile) & Mean $\pm S D$ & Median (quartile) \\
\hline Preparation & $5.2 \pm 3.3$ & $5.0(3.0-7.0)$ & $0.8 \pm 1.0$ & $1.0(0.0-1.0)$ & $9.5 \pm 8.6$ & $8.5(4.0-12.0)$ \\
\hline Administration & $8.0 \pm 7.8$ & $6.0(4.0-10.0)$ & $1.4 \pm 1.9$ & $1.0(0.0-2.0)$ & $6.0 \pm 3.5$ & $5.0(4.0-8.0)$ \\
\hline \multirow[t]{3}{*}{ Total } & $13.2 \pm 9.3$ & $12.0(7.3-16.0)$ & $1.6 \pm 1.9$ & $2.0(0.0-2.0)$ & $14.3 \pm 9.5$ & $13.0(8.3-18.0)$ \\
\hline & \multicolumn{2}{|c|}{$\begin{array}{c}\text { Duration of short interruptions } \\
\text { (second) }\end{array}$} & \multicolumn{2}{|c|}{$\begin{array}{l}\text { Duration of pause to medication } \\
\text { (second) }\end{array}$} & \multicolumn{2}{|c|}{$\begin{array}{c}\text { Duration of total interruptions } \\
\text { (second) }\end{array}$} \\
\hline & Mean $\pm S D$ & Median (quartile) & Mean $\pm S D$ & Median (quartile) & Mean $\pm S D$ & Median (quartile) \\
\hline Preparation & $153.3 \pm 128.8$ & $142.0(67.8-205.0)$ & $88.2 \pm 126.9$ & $44.0(0.0-109.3)$ & $241.5 \pm 215.1$ & $197.5(111.8-344.0)$ \\
\hline Administration & $205.8 \pm 260.3$ & $122.5(70.0-300.8)$ & $132.0 \pm 245.4$ & $46.5(0.0-150.3)$ & $337.7 \pm 371.8$ & $210.5(104.3-432.8)$ \\
\hline Total & $359.0 \pm 289.4$ & $294.0(167.0-479.3)$ & $220.2 \pm 316.5$ & $117.0(40.0-297.5)$ & $579.2 \pm 490.9$ & $458.0(280.0-754.8)$ \\
\hline
\end{tabular}

Table 3. Frequency of interruptions (short interruptions, pause to medication, total) in medication process according to clinics

\begin{tabular}{|c|c|c|c|c|c|c|}
\hline & \multicolumn{2}{|c|}{ Frequency of short interruptions } & \multicolumn{2}{|c|}{ Frequency of pause to medication } & \multicolumn{2}{|c|}{ Frequency of total interruptions } \\
\hline & Mean $\pm S D$ & Median (quartile) & Mean $\pm S D$ & Median (quartile) & Mean $\pm S D$ & Median (quartile) \\
\hline \multicolumn{7}{|c|}{ Preparation } \\
\hline GSS & $6.2 \pm 3.9$ & $5.5(4.0-9.0)$ & $0.7 \pm 1.0$ & $0.0(0.0-1.0)$ & $6.9 \pm 4.0$ & $7.9(4.0-10.0)$ \\
\hline IMS & $4.1 \pm 2.3$ & $4.0(2.0-6.0)$ & $0.9 \pm 0.9$ & $1.0(0.0-1.0)$ & $5.0 \pm 2.6$ & $4.0(3.0-7.0)$ \\
\hline$p$ & \multicolumn{2}{|c|}{$<.001^{* * * *}$} & \multicolumn{2}{|r|}{$>.05$} & \multicolumn{2}{|c|}{.062} \\
\hline \multicolumn{7}{|c|}{ Administration } \\
\hline GSS & $11.5 \pm 9.4$ & $11.5(6.0-14.3)$ & $2.2 \pm 2.4$ & $1.0(0.0-3.3)$ & $13.7 \pm 9.9$ & $11.0(9.0-16.3)$ \\
\hline IMS & $4.6 \pm 3.4$ & $4.0(5.0-6.3)$ & $0.7 \pm 0.8$ & $0.0(0.0-1.0)$ & $5.2 \pm 3.9$ & $4.0(2.0-8.0)$ \\
\hline$p$ & \multicolumn{2}{|c|}{$<.001^{* * * *}$} & \multicolumn{2}{|r|}{$.012^{*}$} & \multicolumn{2}{|c|}{$<.001^{* * * *}$} \\
\hline \multicolumn{7}{|l|}{ Total } \\
\hline GSS & $17.7 \pm 10.7$ & $15.5(11.0-21.0)$ & $1.4 \pm 2.0$ & $0.0(0.0-2.0)$ & $18.6 \pm 10.9$ & $15.5(11.8-22.0)$ \\
\hline IMS & $8.7 \pm 4.6$ & $8.5(5.0-12.0)$ & $1.9 \pm 1.8$ & $2.0(0.0-2.0)$ & $10.1 \pm 5.0$ & $9.5(6.0-14.0)$ \\
\hline$p$ & \multicolumn{2}{|r|}{$.036^{*}$} & \multicolumn{2}{|r|}{$>.05$} & \multicolumn{2}{|c|}{$<.001^{* * * *}$} \\
\hline
\end{tabular}


Table 4. Duration of interruptions (short interruptions, pause to medication, total) in medication process according to clinics

\begin{tabular}{|c|c|c|c|c|c|c|}
\hline & \multicolumn{2}{|c|}{$\begin{array}{l}\text { Duration of short interruptions } \\
\text { (second) }\end{array}$} & \multicolumn{2}{|c|}{$\begin{array}{l}\text { Duration of pause to medication } \\
\text { (second) }\end{array}$} & \multicolumn{2}{|c|}{$\begin{array}{l}\text { Duration of total interruptions } \\
\text { (second) }\end{array}$} \\
\hline & Mean $\pm S D$ & Median (quartile) & Mean $\pm S D$ & Median (quartile) & Mean $\pm S D$ & Median (quartile) \\
\hline \multicolumn{7}{|c|}{ Preparation } \\
\hline GSS & $126.0 \pm 149.9$ & $96.5(48.8-149.8)$ & $94.4 \pm 153.5$ & $23.0(0.0-111.0)$ & $220.4 \pm 275.0$ & $45.5(77.0-290.0)$ \\
\hline IMS & $180.5 \pm 98.8$ & $192.5(100.0-241.3)$ & $82.0 \pm 95.5$ & $52.5(0.0-112.5)$ & $262.5 \pm 132.6$ & $277.5(148.8-380.0)$ \\
\hline$p$ & \multicolumn{2}{|r|}{$.003^{* * *}$} & \multicolumn{2}{|c|}{$>.05$} & \multicolumn{2}{|r|}{.062} \\
\hline \multicolumn{7}{|c|}{ Administration } \\
\hline GSS & $246.2 \pm 339.0$ & $127.0(80.5-351.5)$ & $202.4 \pm 320.7$ & $57.0(0.0-308.0)$ & $448.6 \pm 465.2$ & $239.5(125.0-692.8)$ \\
\hline IMS & $165.3 \pm 139.7$ & $120.0(60.0-245.0)$ & $61.5 \pm 96.9$ & $0.0(0.0-89.8)$ & $226.8 \pm 198.2$ & $161.5(70.0-311.3)$ \\
\hline$p$ & \multicolumn{2}{|r|}{$>.05$} & \multicolumn{2}{|c|}{$>.05$} & \multicolumn{2}{|r|}{$.035^{*}$} \\
\hline \multicolumn{7}{|l|}{ Total } \\
\hline GSS & $372.2 \pm 361.5$ & $284.0(155.3-477.8)$ & $296.8 \pm 415.1$ & $138.0(55.8-420.3)$ & $669.0 \pm 627.4$ & $510.0(309.8-826.8)$ \\
\hline IMS & $345.9 \pm 198.4$ & $310.0(169.5-517.5)$ & $143.5 \pm 139.0$ & $107.0(7.5-272.5)$ & $489.4 \pm 282.8$ & $430.0(265.8-722.3)$ \\
\hline$p$ & \multicolumn{2}{|r|}{$>.05$} & \multicolumn{2}{|c|}{$>.05$} & \multicolumn{2}{|r|}{$.026^{*}$} \\
\hline
\end{tabular}

Note. ${ }^{*} p<.05 ;{ }^{* *} p<.01$

While there was no difference between the services in terms of the duration of short interruptions during the medication process and the administration process, there was a significant difference only in the preparation process. The duration of short interruptions in the preparation process was higher in IMS than in GSS $(p=.003)$. There was no difference between the services in terms of the pause to medication (see Table 4).

\subsection{Findings Regarding the Pauses to Medication}

It was determined that there were pauses to medication in 49 of all the observations $(81.7 \%)$ conducted in both services. There was no statistically significant difference between the services in terms of the frequency of pauses to medication (GSS 86.7\%; IMS 76.7\%) $(p=.027)$. In the preparation process, the rate of total pauses was $63.3 \%$ and there was no difference between the services (GSS 53.3\%; IMS 73.3\%). As for the administration process, the rate of pauses was $55.0 \%$ and there was again no difference between the services (GSS 63.3\%; IMS 46.7\%).

There was no statistically significant difference between the number of pauses to medication according to the services. Nevertheless, when the medication preparation and administration were evaluated individually, pauses in medication preparation was more frequent in GSS than in IMS $(p=.012)$ (see Table 3).

In the medication process, the duration of pauses was 44.0 seconds in preparation while it was 46.5 seconds in administration and 117.0 seconds in medication process (see Table 2 ). There was no significant difference between the services in terms of the total duration of pauses in the medication process (see Table 4).

\subsection{Causes of interruptions}

In descending order of the causes of total interruptions encountered by nurses in the medication process include giving information, medication and equipment,communication, intervention, clinic practice. If there are more it should be listed here othewise leave out etc. However, regarding total pauses to medication, the causes are listed as medication and patient care intervention (an intervention outside the medication such as establishing vascular access, patient positioning, etc.). The reasons for short interruptions were listed as providing information, equipment and medication.

\subsection{People who cause interruption}

People who cause interruption (in descending order of frequency) were listed as hospital employee, patient relative, clinical nurse, physician and student nurse while it was clinical nurse, hospital employee, physician, patient relative and phone in the medication preparation process.

People who cause interruption in the administration process (respectively) were patient relative, hospital employee, patients, nurses and physicians while it was physician, student nurse and other nurses in the service in the preparation process.

There was a positive correlation between the total number of interruptions and the number of patients per nurse, number of medications and number of medications per nurse. However, there was no significant correlation between the durations of interruptions (see Table 5). 
Table 5. Correlation between frequency and duration of interruptions and frequency of patient, and drug

\begin{tabular}{lccc}
\hline & $\begin{array}{c}\text { Frequency of } \\
\text { interruptions }\end{array}$ & $\begin{array}{c}\text { Duration of } \\
\text { interruptions }\end{array}$ & $\begin{array}{c}\text { Number of people/events causing } \\
\text { total interruptions }\end{array}$ \\
\hline Frequency of patient & $.514^{* * *}$ & .105 & $.495^{* * *}$ \\
Frequency of patient per nurse & $.491^{* * *}$ & .086 & $.431^{* *}$ \\
Frequency of drug & $.287^{*}$ & .058 & .239 \\
Frequency of drug per nurse & $.336^{* *}$ & .042 & .234 \\
\hline
\end{tabular}

Note. ${ }^{*} p<.05 ;{ }^{* *} p<.01 ;{ }^{* * *} p<.001$

There was a positive correlation between the number of patients, the number of patients per nurse and the number of people/incidents that caused the interruption. Nevertheless, there was no significant correlation between the total number of medications, the number of medications per nurse and the number of people/incidents that caused the interruption (see Table 5).

\section{Discussion}

Medication administration errors are considered to be among the errors that have a negative impact on patient safety. ${ }^{[26]}$ Nurses often encounter medication administration errors or commit medication errors. ${ }^{[27]}$

Interruptions experienced in the medication process are defined as one of the conditions that cause errors. ${ }^{[28]}$ In the literature, the relationship between interruptions and medication errors have been demonstrated. ${ }^{[4]}$ Interruptions experienced by nurses can jeopardize both their practices and decisionmaking processes. ${ }^{[2]}$ It was demonstrated that interruptions contributed to medication administration errors, ${ }^{[4]}$ as well as loss of concentration, delay in medications ${ }^{[30,31]}$ and that they caused errors. ${ }^{[20,32]}$

In terms of patient and employee safety, it is crucial to ensure that nurses are not distracted during the preparation and administration of medications. ${ }^{[3,16]}$

In our study, interruptions were observed throughout the whole process of medication. In a recent study conducted in the internal medicine-surgery services, neonatal intensive care unit and emergency department, a similar rate of interruption $(99 \%)$ was found in the medication process. ${ }^{[33]} \mathrm{A}$ study conducted in Canada reported that nurses were interrupted by $117 \%$ during medication administration. ${ }^{[16]}$

In studies conducted to determine the interruptions in the medication process, the number of interruptions was found to range widely (1.8 times - 48 times). ${ }^{[1,18,19,33-36]}$ In our study, the number of interruptions for each observation was 13. It is thought that these differences in the results are caused by the methodologies of the studies.
In this study, interruptions were evaluated as short interruptions and pauses to medication. In the medication process, the total number of short interruptions (12) was higher than that of pauses to medication (2). In their study, Johnson et al. ${ }^{[33]}$ found that a nurse left their medication cart to execute another task only once. Then, the nurse came back and continued the medication. No other data was found in similar studies.

In our study, the total number of interruptions in the medication process was higher in the general surgery service. While the number of pauses to medication was similar in both services, short interruption was higher in the general surgery service. The difference in the total number of interruptions was due to the short interruptions. The results obtained in a similar study conducted in the general surgery and internal medicine services are supportive of our results. ${ }^{[30]}$ Studies have shown that nurses in general surgery services are mostly interrupted in the medication process ${ }^{[37]}$ and that general surgery services are one of the services where the highest number of errors are committed. ${ }^{[38]}$ The excessive number of interruptions in GSS is considered to be related with the high number of medications administered (especially IV and SC), and by the higher workload in general surgery services. There is a positive correlation between the number of medications to be administered and the time spent by the nurse at the patient's bedside. In particular, the preparation and administration of IV medications require more time which affects the time spent by the nurse at the patient's bedside and the interruption negatively. General surgery services are the services where the workload of nurses is high and the needs of preoperative /postoperative patients change rapidly. ${ }^{[38]}$ According to the general hypothesis regarding the workload of health workers, it is accepted that there is a positive correlation between the workload and the errors/adverse outcomes. ${ }^{[22]}$

In our observations, it was determined that the number of total interruptions was higher in the preparation process compared to the administration process. These results are in parallel with the findings of similar studies. In their study, Johnson et al. ${ }^{[33]}$ found that the number of interruptions during the medication preparation was higher than that of 
the administration process. It is thought that nurses are interrupted more while preparing medication at the patient's bedside. In similar studies, it is stated that the organization of the medication in proximity to the patient poses a risk of interruption to the process. ${ }^{[1]}$

The studies where nurses prepared the medications in which medications showed that they were interrupted less ${ }^{[1,19,33]}$ found that nurses were interrupted more at the patient's bedside $(47 \%)$ than in the medication room $(16 \%)$ while preparing the medication. In a study conducted to prevent interruptions, a paramedical staff was provided to answer questions to avoid interruptions to the nurse. ${ }^{[33]}$

According to the results of the study, there was a decrease in the rate of interruption/distraction of the nurse. ${ }^{[18]}$ These studies are supportive of our results. However, the necessity of medication preparation in the patient room/corridor should be carefully evaluated in terms of the risks of interruption. When this condition is taken into consideration, it raises the following questions; In order to reduce interruptions, should certain medications be prepared in medication rooms taking into account the duration of their effect? Can the time that nurses spend at the patient's bedside/corridor be reduced in order to reduce interruptions to the medication?

Interruptions, even though they may last short, may distract nurses and cause them to commit errors. In our study, the total duration of interruption times observed in the medication process were higher than some studies (conducted internal medicine services and surgical clinics) ${ }^{[19,33]}$ while they were higher than some others. ${ }^{[35]}$

In our study, the duration of total short interruptions in the medication process was longer than that of the pauses to medication. The total short interruption duration experienced by nurses (approximately $5 \mathrm{~min}$ ) was more than twice the total duration of pauses to medication (approximately $2 \mathrm{~min}$ ). In the literature, although there is no data on the duration of long and short interruptions, the general duration of interruptions in the medication process regardless of the clinics range between $30 \mathrm{sec}-1$ min. ${ }^{[1,33,35,37]}$ Data on pauses were only found in the study of Johnson et al. ${ }^{[33]}$

They found that the nurse stopped the medication only once to be able to respond to the interruption and then returned to the medication.

It was observed that the nurses organized the medication process differently in the services which affected the interruptions and their durations. It was determined that when nurses went to the patient's bedside, they executed other tasks and practices (arranging patient records, positioning the patient, answering patient/relatives' questions etc.); thus, interrupting the medication process. In our study, the duration of total short interruption during medication preparation was higher than that of the administration. This difference may be the result of nurses preparing the medication in the medication cart by the patient's room or the corridor. In their study, Dante et al. ${ }^{[37]}$ determined that nurses were interrupted more in the corridor. In accordance with the literature, our study observed that nurses were interrupted in the corridor by the questions or messages of physicians, patients, patient relatives or staff. In such cases, the nurses were observed to have both responded to the questions and continued preparing the medications. In parallel with our observations, Flanders \& Clark $^{[25]}$ stated that interruptions in medication administration are considered to be routine and acceptable by the work environment. Another cause of interruption in medication preparation was considered to be the number of medications. ${ }^{[37]}$ In the literature, it is stated that the number of medications available is a primary reason why nurses commit errors. ${ }^{[39]}$ In our study, it was determined that the duration of medication was prolonged as the number of medications increased. It was observed that the prolongation of the medication contributed to an increase in the total duration of interruptions.

The total interruption duration was longer in GSS than in IMS. When evaluated according to the stages of the medication process, the duration of interruptions in the GSS was longer during the administration process. Regarding the clinics, the duration of short interruptions was longer in GSS throughout the whole medication process including both the preparation and the administration stages. This was associated with the fact that the total number of medications administered in the general surgery service (especially IV and SC) was high, problems related to the early post-op. period (questions/requests of patients/relatives, IV catheter slipping out of the vein etc.), patients being sent to the operating room and nurses started medication without adequate preparation for medication/equipment. It has been demonstrated that nurses are severely interrupted during the administration of medication due to care coordination. ${ }^{[1,37]}$

In similar studies investigating the differences between the interruptions in different services, a higher number of interruptions were found to occur in IMS contrary to our findings. ${ }^{[30,35]}$ It was thought that this difference was caused by the differences in nursing practices and the organization of medication in services. The duration of interruptions in pauses to medication was longer in GSS at the administration stage while it was longer in IMS at the preparation stage (see Table 4). The reason why the duration of interruptions in pauses to medication was longer in GSS at the administration stage was observed to have stemmed from especially 
the procedures related to the admission of the postoperative patient to the clinic. The nurses stopped their medication and transferred the postoperative patient to their bed. Then, following the primary care given to the patient (vital signs, checking vascular access, analgesic administration etc.), they returned and continued their medication. In the studies conducted previously, it was found that the nurses were mostly interrupted during medication administration due to tasks related with patient care. ${ }^{[1]}$ Biron et al stated that a revision was essential for the management of the medication process due to errors caused by the secondary tasks of nurses in the same period. ${ }^{[1]}$ In the clinics that were observed, it was determined that the nurses themselves created the conditions causing interruptions. For example, nurses postponed some of their responsibilities to undertake them during the medication process. By responding to the requests from patient(s)/relative(s) as "I will be dealing with your problem when I come to your room for the medication", nurses were observed to have given priority to fulfilling their delayed demands by pausing the medication.

It was found that the longer duration of short interruptions in IMS at the preparation stage was caused by lack of medication and equipment in medication carts and nurses' insufficiency regarding the organization of the medication process

In our study, as the number of patients, number of patients per nurse, number of medications and the number of medications per nurse increased, the total number of interruptions and pauses increased. In the studies examining interruptions, it was found that nurses were interrupted more during the hours when the workload in services was high. ${ }^{[40]}$ These results are in parallel with similar studies. ${ }^{[19]}$ This result shows that the number of patients is an effective factor causing total interruption. The positive correlation between the number of patients and the increase in interruptions can be explained by two reasons. First, the number of medications increases as the number of patients increases. Second, nurses' other responsibilities (care, equipment, clinical organization etc.) also increase. In the services that were observed, nurses could not hand over their other responsibilities in the service and care organization even in the medication process (care, getting equipment-medication, preparing/sending the patient for examination, sampling, patient reception, admission/discharge preparation etc.). In our study, the average number of patients per nurse was 7.9 in the GSS and 3.9 in the IMS. These figures are higher than the number of patients per nurse suggested by the WHO. ${ }^{[41]}$ In their study, Palese et al. ${ }^{[40]}$ reported that the frequency of interruptions was higher during the hours when the workload of the nurses was high. While the inadequacy in the number of nurses and clinical organization cause interruptions in the medication process, it also poses a serious risk for nurses and patient safety.

Another positive correlation was found between the number of patients, the number of patients per nurse and the number of people/incidents causing the interruptions. The general hypothesis regarding the workload of health care workers suggests that there is a positive correlation between workload and errors/adverse outcomes. ${ }^{[22]}$ In the services where the research was conducted, the tasks essential to carry out the medication process were not shared. A nurse is also responsible for meeting all the needs of patients. The number of medications used in the general surgery service is higher and the medication process lasts longer. Therefore, the nurse is interrupted more during the medication process.

In the medication process, the causes of total interruptions are providing information, medication and equipment in descending order of frequency. In their study, Dante et al. ${ }^{[37]} \mathrm{de}-$ termined that the duration of interruptions was longer when nurses were interrupted for giving information, training and counselling. The reason for the first interruption in the preparation and administration stages was providing information. It was followed by providing equipment and medication at the preparation stage while it was getting equipment and medication at the administration stage. The reasons for the interruption of medication preparation in this study are similar to the findings of other studies. ${ }^{[19]}$

Similarly, it was determined that $39.6 \%$ of the total interruptions observed in studies were caused by "questions". [16]

Causes of interruption are thought to be due to the inadequacy of the clinical process as well as the inadequate preparation of nurses on the medication and medication control in clini$\mathrm{cal} /$ medication carts. In our observations, it was found that the nurses did not spare enough time for preparation before the medication process started. It was observed that nurses did not make enough preparation (equipment-medication control, vascular access control etc.) due to the fact that they quickly started the medication either following their personal acts (breakfast, conversation with the nurse who handed over the shift etc.) or the daily routines (vital signs, arranging patient records, IV catheter control, pre-op preparation etc.) and that there were severe problems (lack of request from the physician, late delivery from the pharmacy, problems with the transport of medications) regarding the procurement process of medications. These results are in parallel with the studies conducted with similar aims. ${ }^{[3,16]}$ In their study, Buchini \& Quattrin ${ }^{[36]}$ determined that missing medications and prescription were among the most common causes of interruption during the medication administration process.

In our study, the people who caused interruptions were hos- 
pital employee, patient relative, clinical nurse, physician and student nurse in descending order of frequency. Previously conducted studies reported that nurses were in the first place in the list of people causing interruptions contrary to our findings. ${ }^{[16,19,31,35,40,42,43]}$ The reason why hospital employees and patient relatives were at the top of our list was related with the fact that the medication was prepared at the patient's bedside/in the patient room corridor. At the same time, all the nurses in the services were organizing the medication process of their own patients simultaneously and did not interrupt each other except for providing equipment- medication.

In the organization of services, several nursing tasks are required to be conducted at the same time. In this case, interruptions in the medication process are not coincidental. It was also determined that nurses who were constantly being interrupted were not disturbed by these interruptions. ${ }^{[19]}$ As expressed in a paper on this topic, nurses consider interruptions to be a part of their jobs. ${ }^{[3]}$ Throughout the study, it was observed that neither the people who caused the interruptions nor the nurses who were interrupted were not disturbed by these interruptions. Therefore, it is essential that nurses' awareness of interruptions be increased. ${ }^{[4]}$ It is thought that nurses are not careful enough regarding the physician's request and control of the medication-equipment before the medication process. Nurses are certainly being interrupted throughout the medication process.

\section{Conclusions}

Preparing medication at the patient's bedside or in the corridor causes more interruptions for nurses. The interruptions in the general surgery service are higher than those of the internal medicine service. These interruptions may be long enough to keep the nurses away from their work. The nurses were not disturbed by this condition. It is essential that the preparation of medications at the patient bedside/corridor be revised.

\section{Relevance to clinical practice}

Since nurses consider interruptions as "normal" in working life, their awareness is insufficient. Interruptions cause attention distractions in nurses. Interruptions during the medication process are vital. Attention distractions threatens the safety of nurses and patients. Since interruptions vary according to the clinic's internal dynamics, the interruption status and duration should be determined based on the clinics. This study contributes to nurses' and nurse managers' awareness related to interruptions. At the same time, it shows that the interruptions differ according to the clinics. In this case, it indicates that "a uniform type of prevention" should be considered to prevent interruptions in clinics. Most importantly, it is thought to contribute to patient and nurse safety.

\section{Implications for practice}

Since nurses consider interruptions as "normal" in working life, their awareness is insufficient. Interruptions cause attention distractions in nurses. Interruptions during the medication process are vital. Attention distractions threatens the safety of nurses and patients. Since interruptions vary according to the clinic's internal dynamics, the interruption status and duration should be determined based on the clinics. This study contributes to nurses' and nurse managers' awareness related to interruptions. At the same time, it shows that the interruptions differ according to the clinics. In this case, it indicates that "a uniform type of prevention" should be considered to prevent interruptions in clinics. Most importantly, it is thought to contribute to patient and nurse safety.

\section{CONFlicts OF InTEREST Disclosure}

The authors declare they have no conflicts of interest.

\section{REFERENCES}

[1] Biron AD, Lavoie-Tremblay M, Loiselle CG. Characteristics of work interruptions during medication administration. J Nurs Scholarsh. 2009(a); 41(4): 330-36. PMid: 19941577. https://doi.org/10 $.1111 / j .1547-5069.2009 .01300 \cdot x$

[2] Fry M, Dacey C. Factors contributing to incidents in medicine administration. Br J Nurs. 2007; 16(11): 676-881. PMid: 17577187. https://doi.org/10.12968/bjon.2007.16.11.23690

[3] Potter P, Wolf L, Boxerman S, et al. Understanding the cognitive work of nursing in the acute care environment. J Nurs Admin. 2005; 35(7-8): 327-35. https://doi.org/10.1097/00005110-20050 7000-00004

[4] Westbrook JI, Woods A, Rob MI, et al. Association of interruptions with increased risk and severity of medication administration errors. Arch Intern Med. American Medical Association. 2010; 170(8): 683-
90. PMid: 20421552. https://doi.org/10.1001/archintern med. 2010.65

[5] The National Coordinating Council (NCC) for Medication Error Reporting and Prevention. About medication errors. 2011. Available from: http://www.nccmerp.org/aboutMedErrors.html

[6] The Joint Commission on Accreditation of Healthcare Organizations (JCHAO). Available from: https: //www.jointcommission.org/assets/1/18/Stats_wi th_all_fields_hidden30September2010_(2).pdf

[7] Hicks RW, Sikirica V, Nelson W, et al. Medication errors involving patient-controlled analgesia. Am J Health Syst Pharm. 2008; 65(5): 429-40. PMid: 18281735. https://doi.org/10.2146/ajhp07 0194

[8] Berdot S, Gillaizeau F, Caruba T, et al. Drug administration errors in 
hospital inpatients: a systematic review. PLOS ONE. 2013 Jun; 8(6) 2-6. PMid: 23818992. https://doi.org/10.1371/journal.po ne. 0068856

[9] Chang YK, Mark BA. Antecedents of Severe and Nonsevere Medication Errors. J Nurs Scholarsh. 2009; 41(1): 70-8. PMid: 19335680. https://doi.org/10.1111/j.1547-5069.2009.01253.x

[10] Luk LA, Ng WI, Ko KK, et al. Nursing management of medication errors. Nurs Ethics. 2008; 5(1): 28-39. PMid: 18096579. https://doi.org/10.1177/0969733007083932

[11] Eşer I, Khorshid L, Türk G, et al. Determining of factors that nurses can cause medication error. Journal of Ege University School of Nursing. 2007; 23(2): 81-91.

[12] Güneş ÜY, Gürlek Ö, Sönmez M. A. Survey of the patient safety culture of hospital nurses in Turkey. Collegian. 2016; 23(2): 225-32. https://doi.org/10.1016/j.colegn.2015.02.005

[13] Redding AD, Robinson S. Interruptions and geographic challenges to nurses' cognitive workload. J Nurs Care Qual. 2009; 24(3): 194 200. PMid: 19525759. https://doi.org/10.1097/01.NCQ.000 0356907.95076 .31

[14] Kalisch BJ, Aebersold M. Interruptions and multitasking in nursing care. Jt Comm J Qual Patient Saf. 2010; 36(3): 126-32. https : //doi.org/10.1016/S1553-7250(10)36021-1

[15] Monteiro C, Avelar AF, Pedreira Mda L. Interruptions of nurses' activities and patient safety: an integrative literature review. Rev. Lat Am Enfermagem. 2015; 23(1): 169-79. PMid: 25806646. https://doi.org/10.1590/0104-1169.0251.2539

[16] Trbovich P, Prakash V, Stewart J, et al. Interruptions during the delivery of high-risk medications. J Nurs Adm. 2010; 40(5): 211 18. PMid: 20431455. https://doi.org/10.1097/NNA.0b013e 3181da4047

[17] Dickson GL, Flynn L. Nurses' clinical reasoning: processes and practices of medication safety. Qualitative Health Research. 2012 22(1): 3-16. PMid: 21873283. https://doi.org/10.1177/1049 732311420448

[18] Relihan E, O'Brien V, O'Hara S, et al. The impact of a set of interventions to reduce interruptions and distractions to nurses during medication administration. BMJ Qual Saf Health Care. 2010; 19(5): 1-6. PMid: 20511596. https://doi.org/10.1136/qshc. 2009. 036871

[19] Duruk N, Zencir G, Eşer I. Interruption of the medication preparation process and an examination of factors causing interruptions. J Nurs Manag. 2016; 24(3): 376-38. PMid: 26344205. https: //doi.org/10.1111/jonm.12331

[20] Grundgeiger T, Sanderson P. Interruptions in healthcare: Theoretical views. Int J Med Inf. 2009; 78(5): 293-307. PMid: 19081295. https://doi.org/10.1016/j.ijmedinf .2008.10.001

[21] Murphy M, While A. Medication administration practices among children's nurses: a survey. BJN 2012; 21(15): 928-33. PMid: 22874862 https://doi.org/10.12968/bjon.2012.21.15.928

[22] Patient safety and medical errors: the effect of health care working conditions on patient safety. Available from: https://www.ncbi .nlm.nih.gov/books

[23] Aslan O, Ünal C. Parenteral medication errors in surgical intensive care units. Gulhane Medicine Journal. 2005; 47(3): 175-78.

[24] Nguyen E, Connolly PM, Wong V. Medication safety initiative in reducing medication errors. J Nurs Care Qua. 2010; 25(3): 22430. PMid: 20535847. https://doi.org/10.1097/NCQ.0b013e $3181 \mathrm{ce} 3 \mathrm{ae} 4$

[25] Flanders S, Clark AP. Interruptions and medication errors part I, Clin Nurse Spec. 2010; 24(6): 281-85. PMid: 20940564. https: //doi.org/10.1097/NUR.0b013e3181faf78b
[26] Duffield CM, Roche MA, O'Brien-Pallas LL, et al. Glueing it together: Nurses, their work environment and patient safety. 2007. Available from: http://www.health.nsw.gov.au/pubs/2007/ pdf/nwr_report.pdf

[27] Çırpı F, Merih YD, Kocabey MY. Nursing practices that are aims to patient safe and determining the Nurses point view of this topic. Maltepe University Journal of Nursing Science and Art. 2009; 2(3): 29-34.

[28] Reid-Searl K, Moxham L, Happell B. Enhancing patient safety: the importance of direct supervision for avoiding medication errors and near misses by undergraduate nursing students. Inte J Nurs Pract. 2010; 16(3): 225-32. PMid: 20618531. https://doi.org/10.1 $111 / j .1440-172 X .2010 .01820 . x$

[29] Jett Q, George J. Work interrupted: a closer look at the role of interruptions in organizational life. Acad Manage Rev. 2003; 28(3): 494-507. https://doi.org/10.5465/amr.2003.10196791

[30] Hall LM, Ferguson-Pare M, Peter E, et al. Going blank: factors contributing to interruptions to nurses' work and related outcomes. J Nurs Manag. 2010(a); 18(8): 1040-47. PMid: 21073575. https://doi.org/10.1111/j.1365-2834.2010.01166.x

[31] Hall LM, Pedersen C, Fairley L. Losing the moment: understanding interruptions to nurses' work. J Nurs Adm. 2010(b); 40(4): 16976. PMid: 20305462. https ://doi.org/10.1097/NNA .0b013e $3181 \mathrm{~d} 41162$

[32] Biron AD, Loiselle CG, Lavoie-Tremblay M. Work interruptions and their contribution to medication administration errors: an evidence review. Worldviews Evid Based Nurs. 2009(b); 6(2): 7086. PMid: 19413581 . https://doi.org/10.1111/j.1741-678 7.2009.00151.x

[33] Johnson M, Sanchez P, Langdon R, et al. The impact of interruptions on medication errors in hospitals: an observational study of nurses. J Nurs Manag. 2017; 25(7): 498-507. PMid: 28544351. https://doi.org/10.1111/jonm.12486

[34] Berg LM, Källberg AS, Göransson KE, et al. Interruptions in emergency department work: an observational and interview study. BMJ Quality \& Safety. 2013; 22(8): 656-63. PMid: 23584208. https://doi.org/10.1136/bmjqs-2013-001967

[35] Smeulers M, Hoekstra M, van Dijk E, et al. Interruptions during hospital nurses' medication administration rounds. Nurs Rep. 2013; 3(1): 18-23. https://doi.org/10.4081/nursrep. 2013.e4

[36] Buchini S, Quattrin R. Avoidable interruptions during drug administration in an intensive rehabilitation ward: improvement project. J Nurs Manag. 2012; 20(3): 326-34. PMid: 22519610. https: //doi.org/10.1111/j.1365-2834.2011.01323.x

[37] Dante A, Barone F, De Chiara A, et al. Occurrence and duration of interruptions during nurses' work in surgical wards findings from a multicenter observational study. J Nurs Care Qual. 2016; 31(2): 174-82. PMid: 26447344. https://doi.org/10.1097/NCQ.00 00000000000159

[38] Gülkaya E. The level of knowledge about the patient safety of nurses working in intensive care units during the accreditation studies carried out in Hacettepe University adult hospital. Hacettepe Master Thesis, Hacettepe University, Health Management Program. Ankara. 2009.

[39] Institute of Medicine. Keeping Patients Safe: Transforming the Work Environment of Nurses. Washington, DC: The National Academies Press; 2004

[40] Palese A, Sartor A, Costaperaria G, et al. Interruptions during nurses' drug rounds in surgical wards: observational study. J Nurs Manag. 2009; 17(2): 185-92. PMid: 19416421. https://doi.org/10.1 $111 / j .1365-2934.2007 .00835 . x$ 
[41] World Health Organisation (WHO). World Health Statistics 2011. WHO Library Cataloguing-in-Publication Data, ISBN 978 9241564199 (NLM classification: WA 900.1). Available from: https://www.who.int/gho/publications/world_hea lth_statistics/EN_WHS2011_Full.pdf

[42] Hedberg B, Larsson U. Environmental elements affecting the decision-making process in nursing practice. J Clin Nurs. 2004; 13(3): 316-24. PMid: 15009334. https://doi.org/10.1046/j.1365 $-2702.2003 .00879 . x$

[43] Lyons M, Brown R, Wears R. Factors that affect the flow of patients through triage. J Emerg Med. 2007; 24(2): 78-85. PMid: 17251608 https://doi.org/10.1136/emj.2006.036764 